\title{
Arabic version of Acceptable Noise Level (ANL)
}

\author{
Asmaa Ramadan Mahmoud ${ }^{1}$ Amani Mohamed El-Gharib ${ }^{2}$ and \\ Trandil Hassan Elmahallawy \\ Original \\ Article \\ ${ }^{1}$ Resident of Audiology \\ ${ }^{2}$ Assistant Professor of Audiovestibular medicine Audiology Unit, Department of ENT \\ ${ }^{3}$ Professor of Audiology, Audiology Unit, Department of ENT, Faculty of Medicine, \\ Tanta University, Egypt
}

\begin{abstract}
Background: ANL is a procedure to evaluate the quantity of noise that listeners are willing to take over while listening to words. ANL has gained big attention in the final few years because of its ability to predict success rate of hearing aid with a high degree of accuracy. Knowing why certain people are less probable to accept background noise help in creating hearing aid technology to address their objections and improve their ANL hence increasing success rate of hearing aid function.

Objectives of the study: development and Standardization of Arabic version of ANL in Egyptian normal hearing listeners. Materials and method: 52 normal hearing adults undergo this research. ANL was performed using an Arabic familiar story $40 \mathrm{Sec}$ duration and competing background noise of multitalker babble. Both stimuli were routed through the same loudspeaker located at zero azimuth $1 \mathrm{~m}$ from the subject in a sound treated room.

The results: the mean ANL of the Arabic version in participant with normal hearing is $7.76 \mathrm{~dB}$ with a standard deviation of 3.55 .

Conclusion: the new Arabic version of acceptable noise level (ANL) can be applied as a standardized test for measuring acceptable noise level.
\end{abstract}

Key Words: Acceptable noise level, arabic version, normal data.

Received: 04 October 2018, Accepted: 24 December 2018

Corresponding Author: Amani Mohamed El-Gharib, Assistant Professor of Audiovestibular medicine Audiology Unit, Department of ENT, Tel.: +20 1098469400, E-mail: amanielgharib@yahoo.com

ISSN: 2090-0740, November 2018, Vol.19, No. 3

\section{INTRODUCTION}

Acceptable noise level (ANL) is the maximal sum of ground interference that a listener is willing to put up with while listening to running speech. ${ }^{[1]}$ Nábělek et al ${ }^{[2]}$ introduced a routine to measure ANL by calculating the remainder between the most comfortable stage of speech (MCL) and ground noise level (BNL). Their results indicated that the ANL was directly linked to successful hearing aid function.

It is important to distinguish between spoken language understanding in noise and willing to listen in noise. ANL is not related to performance on a dissimilar type of languagein noise measure. The Speech-in-Noise test (SPIN) measures comprehension of sentences in noise (a complex linguistic process), while ANL measures willingness to allow background noise while taking heed to the quarrel of a report (no linguistic process). Consequently, ANL and SPIN test each provide unique information about a patient's abilities. ${ }^{[3]}$ SPIN scores improve with amplification and can be applied as a criterion of benefit from amplification, but it, cannot anticipate who will be a successful user of hearing aids. The ANLs do not change with use of amplification and appear to forecast who will likely be proficient users of learning aids, even before they are fitted. ${ }^{[4]}$

Knowing ANL may help those who fit hearing aids providing better counseling to people with hearing loss. Additionally, if we can see why certain people are less likely to be successful with hearing aids, and so we may be able to create technology that comes up to their objections to background noise and thus improves their prospects of success with hearing aids. ${ }^{[1]}$ Because of the above, we designed the work to modernize and standardize Arabic version of acceptable noise. 


\section{SUBJECTS AND METHOD}

Subjects

This survey included 52 normal peripheral hearing adults with an age range of 18-50 years. The subject area was sanctioned by The Research Ethics Committee (approval code 30759/02).

\section{Method}

- Basic audiological evaluation: by Madsen Astera which is a Type-1two channel, and PC-based audiometer with with headphone TDH 39, Acoustic immittance measurements (tympanometry/stapedial reflex) by interacoustics AT235H impedance low frequency $226 \mathrm{~Hz}$ probe tone (Middelfart, Denmark).

Speech audiometry including:

a. Speech Recognition Threshold (SRT) using the Arabic bisyllablic word.

b. Word Discrimination Score (WD) using Arabic phonetically balanced word.

- $\quad$ Acceptable noise level (ANL) test:

Acceptable noise level test material:

Speech stimulus: An Arabic story recorded by a female native speaker. The speaker is an Audiologist with professionally trained voice and she was understanding the purpose of the test. She was taught to preserve clarity, pace, and effort while learning the report. The narration is very coarse and well recognized in our Arab world (the rabbit and the turtle). It was recorded on Zoom H1 Handy Recorder which is a brilliant Stereo recorder. The recorded story was sampled as WAV to $24-\mathrm{bit} / 96 \mathrm{KHz}$ which used for high resolution recordings. Recordings were made in a doublewalled sound treated room. An X/Y microphone designed to capture perfect stereo images with remarkable depth and clearness. The mike was positioned perpendicular to the loudspeaker at a distance of $1 \mathrm{~m}$. Average signal levels at the microphone were maintained at about $65-70 \mathrm{~dB}$ SPL. The continuance of the story is about $40 \mathrm{Sec}$.

Background noise: competing background babble noise was a mix of 4 multitalkers. Speakers were one male and three females. Recording was done by the same procedure mentioned before.

\section{ANL test procedure:}

Both the speech stimulus and the competing background noise were routed through the audiometer to the same loudspeaker (MARTIN-AUDIO LONDON) located at zero azimuth $1 \mathrm{~m}$ from the subject in a sound treated room.
Determining the most comfortable level (MCL): the story runs at first and listeners were instructed to raise their hands when the story was uncomfortably loud, too soft and comfortable to them. Five dB steps were used for rough adjustment and two $\mathrm{dB}$ steps for fine fitting.

Setting the background noise level (BNL): the story run at MCL and background noise was added through the same speaker. Auditors were asked to put up their hands when story is incomprehensible, very well-defined and when they can trace the account without being tired from background interference. BNL was recorded.

ANL was calculated by subtracting BNL from MCL.

- $\quad$ Statistical Data were analyzed using the Statistical Program for Social Science (SPSS) version 21. Quantitative data were expressed as a mean \pm standard deviation (SD).

- Any unexpected complication that will come out during the course of the research will be cleared to the participants and to the ethical committee on time.

- Every participant will deliver a code number.

- The outcomes of the research will be applied only in scientific use.

- The idea of the research will be explained in details to the participants and also possible complications and side effect.

- An informed consent was obtained from all participants in this query.

- The participation is voluntary and that subject may discontinue participation at any time without penalty or loss of benefits.

\section{RESULTS}

It consisted of 52 adults 18 males $(34.6 \%)$ and 34 females $(65.4 \%)$. Their age ranged from $18-50$ years. The mean age was 28.65 with a standard deviation of 6.43 . They totally received a bilateral normal peripheral hearing in the frequency range of $250-8000 \mathrm{~Hz}$ (hearing threshold level were $\leq 25 \mathrm{dBHL}$ ). Mean and SD of PTA thresholds from 250 to $8000 \mathrm{~Hz}$ was $13.13 \pm 5.49 \mathrm{dBHL}$. Comparison of pure tone air conduction thresholds at different frequencies was done between right and left ears showed no statically significant difference.

III.a. Most comfortable level (MCL) and ground noise level (BNL)

The mean MCL was $50.96 \mathrm{~dB}$ HL with a standard deviation of 6.11. The mean BNL for the control group was $43.07 \mathrm{~dB}$ HL with a standard deviation of 6.26. Table (1). 
Table (1): Mean, Standard deviation (SD), Range and confidence (95\% CI).

\begin{tabular}{ccccc}
\hline & Mean & SD & Range & $95 \% \mathrm{CI}$ \\
\hline ANL & 7.76 & 3.55 & $0-16$ & $6.79-8.72$ \\
\hline
\end{tabular}

III.b. Acceptable noise level results:

ANL was calculated by subtracting BNL from MCL $\mathrm{ANL}=\mathrm{MCL}-\mathrm{BNL}$ For the control group the ANL range was (0-16) The mean ANL was $7.76 \mathrm{~dB}$ with a standard deviation of 3.55 . 95\% confidence interval (CI) was 6.798.72. Table (1).

In parliamentary law to see the correlation between ANL and the other measures collected in this study, correlations between ANL, age and gender were calculated and no important association was set up between the ANL and age, hearing threshold level or gender (Table 2, 3).

Table (2): Correlation between ANL, pure tone average and age.

\begin{tabular}{ccc}
\hline & \multicolumn{2}{c}{ ANL } \\
\cline { 2 - 3 } & $\mathrm{R}$ & $\mathrm{P}$ \\
\hline Pure tone average & .659 & .063 \\
Age & .563 & .082 \\
\hline
\end{tabular}

Table (3): Relation between Sex and ANL.

\begin{tabular}{ccccccc}
\hline & \multicolumn{2}{c}{ Male } & \multicolumn{2}{c}{ Female } & & \\
\cline { 2 - 5 } Items & Mean & SD & Mean & SD & Test of sig. & p-value \\
\hline ANL & 7.67 & 2.84 & 9.17 & 5.0 & $\mathrm{t}=1.105$ & 0.277 \\
\hline
\end{tabular}

The objective of this work is to determine ANL in normal hearing using a new Arabic edition of the ANL test, the mean ANL for 52 adults with normal hearing

Sensitivity was $7.76 \mathrm{~dB}$ with a standard deviation of 3.55. Our outcomes were similar to previously reported results from English studies. ${ }^{[2,5,6,7,8,9,10,11,12]}$

Participants evaluated by the Australian ANL test recorded a lower mean than reported in our and most other studies by about $(5-6 \mathrm{~dB})$, The ANL has a mean of $4.1 \mathrm{~dB}$ and a standard deviation of $5.5 \mathrm{~dB}$. In the Australian study stimuli were presented idiotically through earphones. 13 In the current work, we used loudspeakers.

Chen et al. 14 used Chinese (Mandarin) language to evaluate the Mandarin speech signal content on the acceptable noise level (ANL) test in listeners with normal hearing in mainland China. Mean ANL was 7.6 with a standard deviation of 5.0. Their results are quite similar to this study 15

ANL has been studied using Danish and Swedish materials. Mean ANLs between 5.6 and $16.6 \mathrm{~dB}$ respectively, and SDs between $6.9 \mathrm{~dB}$ and $10.2 \mathrm{~dB}$ respectively, depending on the study population (Danish or Swedish) and test condition ${ }^{[14]}$

Possible grounds for varying effects from different fields are almost probable to be procedural or extrinsic in nature. In terms of procedure, the modality of delivery was variable among different subjects. In most studies speech and noise were either presented unilaterally through earphones, or bilaterally in the free field. ${ }^{[13]}$

Harkrider and Smith 16 compared different modes of delivery and found a mean deviation of $2 \mathrm{~dB}$ between magnetic and dichotic presentation, defending the idea that different ways of delivery could influence the ANL.

This research results agreed with the immense bulk of studies which suggested that there is no relationship between ANL age, sex and hearing thresholds reported as the average pure-tone hearing thresholds $\mathrm{s}^{[2,3,6,8,16]}$.

In summary, the new Arabic version of ANL can be used as standardized test for measuring acceptable noise level. The mean ANL of the Arabic version in participant with normal hearing is $7.76 \mathrm{~dB}$ with a standard deviation of 3.55. ANL was categorized into 3 groups low when ANL values were equal or less than $6 \mathrm{~dB}$, high ANL when values were equal or more than $14 \mathrm{~dB}$ and mid group with ANL values between (6-14 dB). No correlation was found between ANL and age and gender.

We recommend Apply Arabic ANL to all patients with hearing loss for better counseling about benefits of hearing aid before fitting. Future researches on ANL in patients with sensory neural hearing loss and auditory neuropathy. We also recommended Appling ANL in children to identify children at risk of encountering listening problems at school.

\section{REFERENCE}

1. Recker K, McKinney M, Edwards B. Loudness as a cue for acceptable noise levels. Journal of the American Academy of Audiology. 2014; 25: 605-623.

2. Nábělek A, Tucker F, Letowski T. Toleration of Background Noises Relationship with Patterns of Hearing Aid Use by Elderly Persons. Journal Speech Hear Res. 1991; 34: 679-685.

3. Nábělek A, Tampas J, Burchfield S. Comparison of speech perception in background noise and acceptance of background noise in aided and unaided conditions. Journal of Speech, Language, and Hearing Research. 2004; 47: 1001-1011. 
4. Taghavi S, Geshani A, Rouhbakhsh N \& Mardani $\mathrm{S}$. Acceptable noise level test: bases and theories. Auditory and Vestibular Research. 2017; 26: 184194.

5. Roger D, Harkrider A, Burchfield, S. \& Nabelek A. The influence of listener's gender on the acceptance of background noise. Journal of the American Academy of Audiology. 2003; 14: 37282; quiz 401.

6. Freyaldenhoven M, Smiley D. Acceptance of Background Noise in Children with Normal Hearing. Journal of Educational Audiology. 2006; 13: 27-31.

7. Freyaldenhoven M, Plyler P, Thelin J, Hedrick M. The Effects of Speech Presentation Level on Acceptance of Noise in Listeners with Normal and Impaired Hearing. Journal of Speech Language and Hearing Research. 2007; 50: 878.

8. Gordon-Hickey S, Moore R. Influence of music and music preference on acceptable noise levels. Journal of the American Academy of Audiology 2007; 18: 417-428.

9. Gordon-Hickey S, Moore R. Acceptance of noise with intelligible, reversed, and unfamiliar primary discourse. American Journal of Audiology 2008; 17: 129-135.

10. Plyler P, Alworth L, Rossini T, Mapes K. Effects of speech signal content and speaker gender on acceptance of noise in listeners with normal hearing. International Journal of Audiology2011; 50:243-348
11. Plyler P, Bahng, J, von Hapsburg D. Acceptance of noise in adult Cochlear implant users. Journal of Speech, Language, and Hearing Research 2008; 51:502-515.

12. Plyler P, Madix S, Thelin J, Johnston K. Contribution of High-Frequency Information to the Acceptance of Background Noise in Listeners with Normal and Impaired Hearing. American Journal of Audiology 2007; 16: 149.

13. Walravens E, Keidser G, Hartley D, Hickson L. An Australian version of the acceptable noise level test and its predictive value for successful hearing aid use in an older population. International Journal of Audiology 2014; 53: S52-S59.

14. Chen J, Zhang H, Plyler P, Cao W, Chen J. Development and evaluation of the Mandarin speech signal content on the acceptable noise level test in listeners with normal hearing in mainland China. International Journal of Audiology.2011; 50:354-360.

15. Brännström K, Lantz J, Nielsen L. \& Olsen S. Acceptable noise level with Danish, Swedish and non-semantic speech materials. International Journal of Audiology. 2012; 51:146-156.

16. Harkrider A, Smith S. Acceptable Noise Level, Phoneme Recognition in Noise, and Measures of Auditory Efferent Activity. Journal of the American Academy of Audiology. 2005; 16: 530-545. 